\title{
ERRATUM
}

\section{Copper-catalysed selective hydroamination reactions of alkynes}

Shi-Liang Shi and Stephen L. Buchwald

Nature Chemistry 7, 38-44 (2015); published online 15 December 2014; corrected after print 18 December 2014.

In the version of this Article originally published, the red arrow at the top right of Fig. 1c should have been solid not dashed. This has now been corrected in the online versions of the Article.

\section{CORRIGENDUM}

\section{Optimized orthogonal translation of unnatural amino acids enables spontaneous} protein double-labelling and FRET

Kaihang Wang, Amit Sachdeva, Daniel J. Cox, Nabil M. Wilf, Kathrin Lang, Stephen Wallace, Ryan A. Mehl and Jason W. Chin Nature Chemistry 6, 393-403 (2014); published online 20 April 2014; corrected after print 7 January 2015.

In the version of this Article originally published, the middle initial of the co-author Nabil M. Wilf was incorrect, and the Acknowledgements section was missing a reference to the European Research Council; the statement should have read: "We thank the Medical Research Council (U105181009, UD99999908) and the European Research Council (MC-A024-PG0A) for financial support. We thank S-P. Chew (MRC-LMB Mass Spectrometry) for obtaining MALDI data." These errors have now been corrected in the online versions of the Article. 